\title{
Correction to: Concurrent psychiatry for patients enrolled in opioid agonist treatment: a propensity score matched cohort study in Ontario Canada
}

Kristen A. Morin ${ }^{1}$, Joseph K. Eibl ${ }^{2}$, Joseph M. Caswell ${ }^{6}$, Graham Gauthier ${ }^{2}$, Brian Rush ${ }^{4}$, Christopher Mushquash ${ }^{2,5}$, Nancy E. Lightfoot ${ }^{1}$ and David C. Marsh $2,3^{*}$

Correction to: Subst Abuse Treat Prev Policy (2019) 14: 29

https://doi.org/10.1186/s13011-019-0213-6

Following publication of the original article [1], we have been notified that the following changes should occur in the content of the article. The details are below.

1. Table 1 and Table 2: the last section on OAT retention pertaining to treatment retention was only conducted on a subcohort of the population and therefore the numbers are not accurate and should be removed.

2. The article Outcome section on OAT retention should be removed because retention was not used as covariate.

\section{Author details}

${ }^{1}$ Laurentian University, Sudbury, Canada. ${ }^{2}$ Northern Ontario School of Medicine, Sudbury, ON P3E 2C6, Canada. ${ }^{3}$ Canadian Addiction Treatment Centres, Richmond Hill, ON, Canada. ${ }^{4}$ Centre for Addiction and Mental Health, Toronto, Canada. ${ }^{5}$ Department of Psychology, Lakehead University, Thunder Bay, Canada. Institute of clinical and Evaluative Sciences, Sudbury,

ON, Canada.

Published online: 06 November 2019

\section{Reference}

1. Morin KA, et al. Concurrent psychiatry for patients enrolled in opioid agonist

treatment: a propensity score matched cohort study in Ontario Canada.

Subst Abuse Treat Prev Policy. 2019;14:29. https://doi.org/10.1186/s13011-

019-0213-6.

\footnotetext{
* Correspondence: dmarsh@nosm.ca

${ }^{2}$ Northern Ontario School of Medicine, Sudbury, ON P3E 2C6, Canada

${ }^{3}$ Canadian Addiction Treatment Centres, Richmond Hill, ON, Canada

Full list of author information is available at the end of the article
}

(c) The Author(s). 2019 Open Access This article is distributed under the terms of the Creative Commons Attribution 4.0 International License (http://creativecommons.org/licenses/by/4.0/), which permits unrestricted use, distribution, and reproduction in any medium, provided you give appropriate credit to the original author(s) and the source, provide a link to the Creative Commons license, and indicate if changes were made. The Creative Commons Public Domain Dedication waiver (http://creativecommons.org/publicdomain/zero/1.0/) applies to the data made available in this article, unless otherwise stated. 